\title{
MUSIC AS A FACILITATOR FOR SKILL DEVELOPMENT: REVISITING THREE YOUNG FIRST NATIONS INDIVIDUALS ON THE AUTISM SPECTRUM
}

\section{Anne Lindblom}

Associate professor in special education. Inland Norway University of Applied Science, Postboks 400 2418 Elverum (NORWAY)

Senior lecturer in special education. Karlstad University, Universitetsgatan 2, 65188 Karlstad (SWEDEN)

Honorary Research Fellow. Northern Institute and College of Indigenous Futures Arts and Society. Charles Darwin University, Ellengowan Drive, Casuarina, NT 0810 (AUSTRALIA)

\section{Eduport 5 (1) - Reviewed Papers \\ DOI: 10.21062/edp.2021.004}

\begin{abstract}
Indigenous children and young people on the autism spectrum are scarce in research publications. This article revisits three research partners, Connor, Debbie and Tom, in a follow-up study of a PhD project on the meaning of music for First Nations children on the autism spectrum in British Columbia, Canada. An Indigenist research framework was used in the project with conversations as the methodology. It would seem like the First Nations children on the spectrum would have similar life situations, but results show diverse barriers and opportunities for them to participate and influence their lives. Living on or off reserve is one aspect. Music plays a large role in their lives in various ways. It will be shown how music facilitates the development of self-regulation for the three young people, and social skills for one of them. The vital importance of culturally appropriate and sensitive diagnosis processes, autism services and special educational actions and activities will be discussed as steps towards fully inclusive, equitable, and decolonized education for Indigenous children and young people. Such measures will be beneficial for diverse learners across the globe.
\end{abstract}

Keywords: First Nations, autism spectrum disorder, music, skill development, cultural sensitivity, inclusion, equity, decolonization

\section{INTRODUCTION}

Music is a big part of the everyday environment for many people, and for some, it is an essential component. For young people, music can be fundamental as they develop their personal and social identities [1]. Music can be used to self-regulate emotions [2]. Consolation can be found in music and can be a way to handle grief after the loss of a loved one [3]. Aggression can come both from lack of empathy and high levels of empathy [4]. Empathy can be positively influenced by musical interactions in group settings [5]. Autism spectrum disorder, ASD, is a neuro-developmental condition that affects the individual's social communication and interaction, and is also represented by restricted and repetitive behaviors [6]. These traits impact how individuals interact with others, and can affect their social inclusion in educational settings, as difficulties can occur in regulating emotions, making friends or expressing extreme concern or anxiety in response to change [6]. Young people on the autism spectrum often show an inclination towards music [7]. They use music for similar purposes as neuro-typical youngsters. Music can also be a form of non-verbal communication for individuals on the autism spectrum [7]. This has also been found in regard to First Nations children on the autism spectrum [8,9].

There are three Indigenous peoples recognized by the Canadian government; First Nations who still are referred to as Indians in certain official documents, Inuit and Métis [10]. First Nations is the term used in this article about the Indigenous peoples who sometimes are referred to in official documents as Indians [10]. The choice of terminology is to promote decolonization. To address power issues in the research context, the term 
conversation is used instead of interview, and research partner instead of participant. I am a non-Indigenous, Swedish researcher that grew up in Canada, and my stepmother and three paternal sisters are from the Carrier Nation. This, and the fact that I have done research within an Indigenist paradigm, entails the use of respectful and culturally appropriate terminology. The young people in this research project are from different Nations, so the research has a pan- Indigenous approach. First Nations individuals can have what is called Indian status, which is the legal status that means the person is registered as an Indian under the Indian Act [11]. Having Indian status gives eligibility to services, rights, benefits and programs. It appears that First Nations individuals are under-detected for ASD [12]. Previous research shows that First Nations children on the autism spectrum for various purposes, but that music interventions lack cultural sensitivity [8]. Music interventions and cultural competence is a field that requires more research [13]. The main purpose of this article is to explore how young First Nations persons on the autism spectrum can develop skills through the use of music to further inform research and practice.

\section{THE PROJECT}

In this section the project will be described from how it formed from a PhD project. Then the theoretical frame will be briefly outlined.

\section{Background}

In a small scale, qualitative, longitudinal study on the meaning of music for First Nations children with autism in B.C, Canada, five children and people close to them participated in a PhD study in which the two first waves were incorporated. The people around the children were parents and other family members, caregivers, teacher, support worker and other professionals. In the first wave 2013, and second wave 2014, the data consisted of conversations, filmed interactions with music, observations (note-taking or filmed) and field notes. Additionally, a music intervention was done with one of the children in 2014.

\section{Wave 3}

The data used in this article is from the third wave of data collection in which three of the original five First Nations children on the autism spectrum consented to participate in conversations in 2017. The data collection in wave 3 was done when the researcher was solely affiliated with Karlstad University, Sweden. The fourth wave was planned for 2020, but the covid-19 pandemic made it necessary to postpone the research in 2021 as well. This may mean that there will be four waves in the end, and that 2023 is an option to do the last wave of collection.

The method in this third wave of data collection was conversations. The conversations were recorded and transcribed in verbatim. As Connor is minimally verbal and could not participate, but his family members engaged in conversation. For this publication, the data was examined in regard to the specific challenges of the three research partners and how music facilitated the development of the skill. In 2013 and 2014, the transcripts were transformed into visual maps from themes that appeared. These maps were used as a focal point in the conversations in the third wave of data collection in 2017. However, in this particular article, the themes are self-regulation and social skills, so consequently the transcripts were coded from these themes in the color purple for how the children use music themselves. In the picture below it is the conversation between the researcher: $\mathrm{R}$ and Tom: $\mathrm{T}$

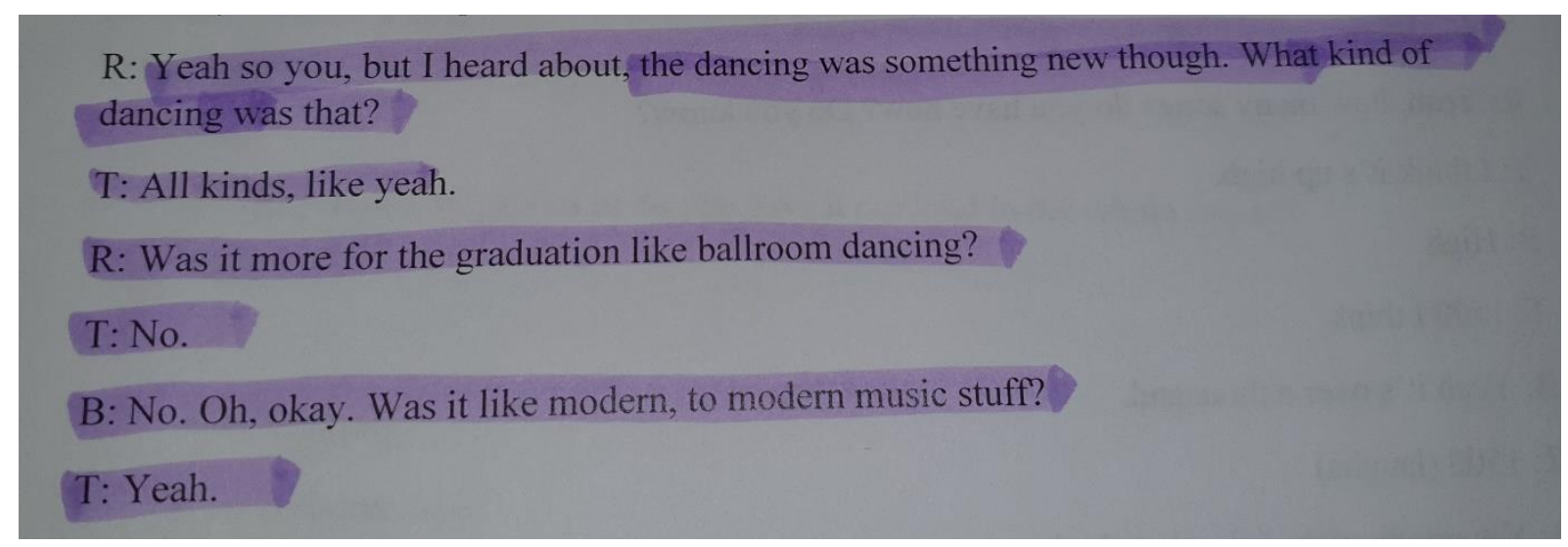


Picture 1: example of color coding.

Color coding of the data was done manually and a circular approach was used, which is common in Indigenous and Indigenist paradigms [14]. This entailed reading the transcripts, reflecting, coding and then repeating the circle until the themes clearly presented themselves. The use of visual maps as a focal point also harmonizes with a circular approach as their form is circular and the conversations followed the maps in a clockwise order.

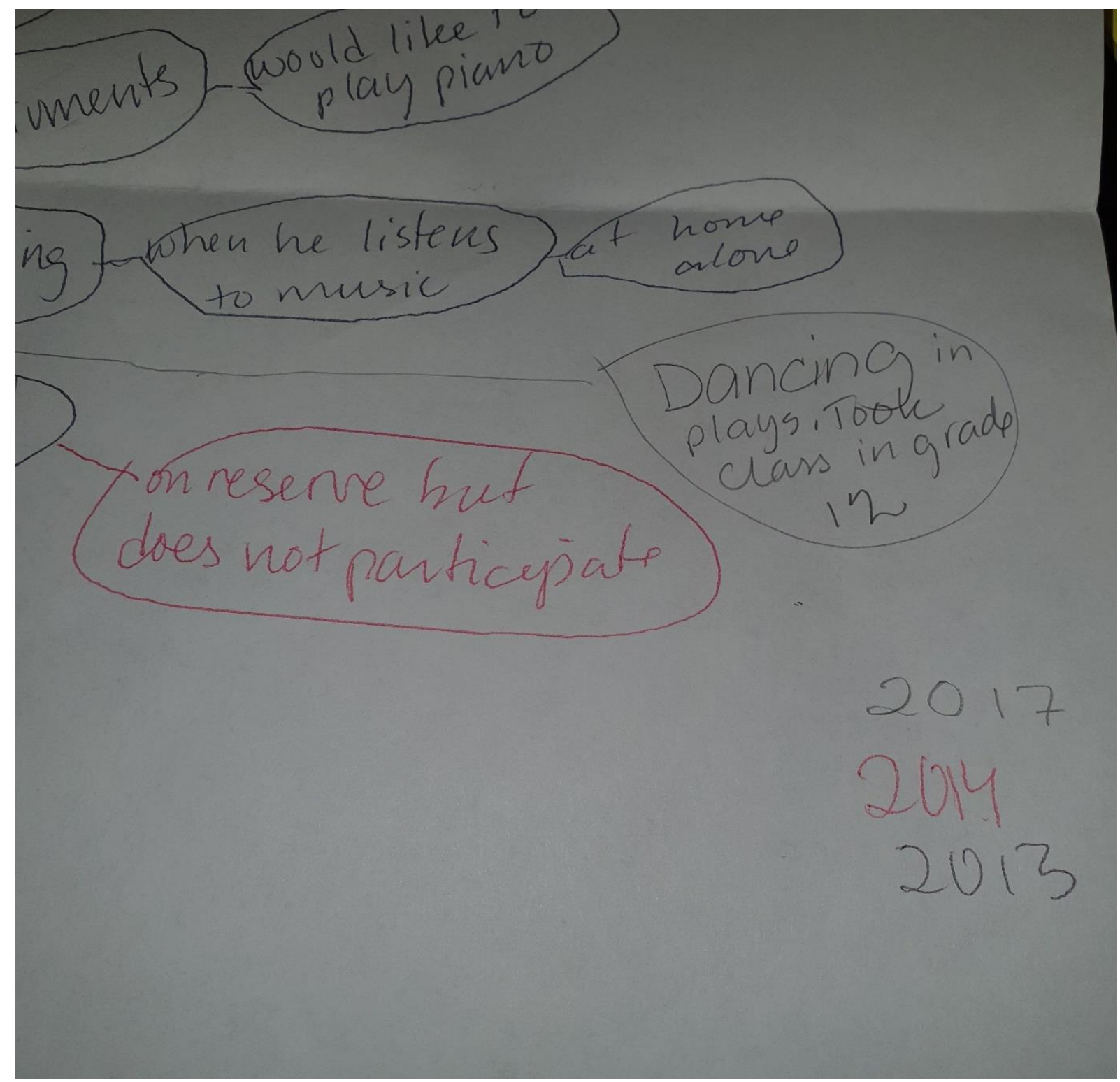

Picture 2: Part of Tom's Visual map with the black from 2013, red additions from 2104 and grey additions from 2017.

There are very few First Nations individuals diagnosed with ASD. To assure anonymity all names have been changed. Living locations and other information has been omitted. Conversation transcripts will not be available to readers. Ethical approval was given from Karlstad University, Sweden. Informed consent was given in writing, but also negotiated during the conversations.

\section{Theoretical framework}

This project was done within an Indigenist paradigm. This means that Indigenous ways of knowing, being and doing, or in other words the philosophical assumptions, underlie the research, and the research harmonizes with the philosophical assumptions. As a non-Indigenous researcher, it is possible to take this stance; "This emphasizes that it's a philosophical issue, not a claiming of ownership by one group of people. You can be a 
white Indigenist just like you can be a male feminist" [15]. In contrast to the medical model of disability [16], this article is grounded in an Indigenist model [17]. Key concepts in this model are: inclusion, reciprocity, relationality, respect and reflexivity. The model is child-centered, and interventions should be culturally sensitive. For the model to be Indigenous, the interventions would be culturally specific, delivered in the specific language, in accordance with traditional protocols and traditional knowledge.

\section{RESEARCH PARTNERS}

Three First Nations children and young people participated in the conversations we had in 2017. The same fictitious names as in previous publications are used to facilitate connecting the publications and following progress $[8,9]$. The data was collected during affiliation with Karlstad University, Sweden, and since then, the author has changed main affiliation.

\section{Connor}

Connor was 10 years old in 2017. He has Indian status and lives together with family members who took him in and eventually gained formal custody of him when he was a baby after his mother passed away. They live on reserve. He received his autism diagnosis when he was approximately one year old and had an ASD special needs classification when he attended school. Connor is minimally verbal and did not participate in any conversations. Previously, the mother figure Elizabeth, a teacher's aide Anna, grandfather figure Earl, Todd the uncle figure and a principal of Aboriginal Education, David, participated. In the third wave the participants in regard to Connor were Elizabeth, Todd and an auntie living in the home, Elinor, who also considers herself to be a mother figure. Connor enjoys listening to music and dances and hums all the time. He uses humming for communication. Connor listens to whatever the family listens too and his preference has changed over time from nursery rhymes to pop music. He only heard Indigenous music on the TV when his grandmother figure was still alive but going to traditional events and ceremonies was too overwhelming. This, along with the fact that he often tries to run away and can be aggressive, has led to the family mostly being confined to their home on the reserve. The family thought one-on-one drumming and singing might be a good option [8, 9].

\section{Debbie}

Debbie was 18 years old when we met in 2017. She has Indian status and lives with her mother off reserve. Her father passed when she was quite young. Debbie received her autism diagnosis when she was four years old and had an ASD special needs classification during her school years. This was supposed to be her last year of highschool, but she was going to do an extra year. Previously, her mother Grace, after school aide Emily, resource room teacher Mona, music therapist Victoria and Sandra who is an Aboriginal support worker participated. In the third wave, Debbie and her mother Grace participated. Music has always been a fundamental aspect of Debbie's life. Through her ability to sing and learn the latest pop-songs, she was able to be socially included at the after-school club she used to attend. Debbie used music for purposes such as relaxation, security, happiness, self-soothing. Mona thought Debbie made the world a safer place for herself when listening to music. Debbie did not listen to Indigenous music or go to cultural events, but she had made a drum previously in Aboriginal class that she enjoyed playing. A big challenge for her was to manage her emotions that led to violent tantrums and rage when she heard a specific song. This song was thought to make her very sad and that she could not handle the grief. These outbursts made it necessary for someone to accompany Debbie as much as possible, which sometimes had a negative impact on her social inclusion $[8,9]$.

\section{Tom}

Tom was 19 years old when we met in 2017. He has Indian status and lives off reserve with his adoptive family. When he was six years old he was diagnosed with Fetal Alcohol Syndrom, Oppositional Defiant Disorder, problems with anger management and Attention Deficit Hyperactivity Disorder. A year later the diagnosis ASD was added. Tom is what sometimes is referred to as high functioning and attended a regular class in school. He had an ASD special needs classification up until he was 15 years old. Previously, Tom, his adoptive mother Patty, drama teacher Evelyn and an educational coordinator, Rita, participated. In the third wave, Tom and Patty participated. Music is a large part of Tom's life. He used music for relaxation, when studying, and basically in all his free time. He still was in contact with his Indigenous birth-family and participated in cultural events when he was younger. He used to sing and drum a song from his Nation which calmed him down. The last time he was at a potlatch was in 2013. Tom participated in musicals in high school. Patty thinks he makes a safe place for himself with music. Tom is shy, but thanks to his interest in music, he could actively participate in school events $[8,9]$. 


\section{RESULTS}

The results from the conversations in 2017 are presented in light of the challenge the child or young person has been struggling with and how music over time facilitated skill development.

\section{Connor: self-regulation}

In 2017, Connor had been banned from school because they could not handle his behavior and he often ran away from school. Elizabeth was hoping to get him in to the Indigenous school where they teach their language and culture. Todd thinks that the lashing out comes from Connor being in pain and not being able to tell them. They had been to a nearby city recently so Connor could have several teeth taken out which Todd hoped would help. Todd says that Connor understand both English and their language but cannot speak. Todd thinks they could get better help if they moved to a larger city like Vancouver, but he is a bit afraid of that since he has never lived anywhere else but on the reservation. Some people think they should give Connor up and put him in a home, but Todd (June 16th, 2017) says "...we treat him like a regular boy and he loves it". According to Elinor, Connor is very passionate about music.

And I've noticed what mainly makes him normal is the native drums...Cause every time he hears them he normally just sits and he's just quite normal actually...because there's quite a few songs from the native ones that he likes...And I've noticed this one called Hello mother that he seems to know very well because he could drum it himself...A song like that from the natives takes years to learn and my uncle who is an Elder with a big name, he sang it to Connor before and he learnt it in one session. (Elinor June 12th, 2017)

Similarly to the occasion when Connor could take turns and take eye contact with the researcher in 2014 [8], the family experiences that Connor has access to competences, such as the ability to calm down and to learn songs, when his language and traditional music is used. This opportunity has not been utilized in the school settings. Since Connor has been banned from the school, it would appear that the chance of him receiving culturally specific music interactions in an educational setting seems unlikely. As the family lives in a rural area, there are few services available.

\section{Debbie: self-regulation}

Grace says that it has been a turbulent time for the past one and a half years in which Debbie's tantrums have escalated. However, the past weeks before our conversation, her emotions have settled. These outbursts can be unpredictable and it is very difficult, and sometimes impossible, to end the tantrum. There is a Canadian group that has one particular song that previously used to cause Debbie to have a tantrum every time she heard it. In 2013, this had been going on for four years and Debbie sometimes could somewhat soothe herself when she heard it.

Of course they're getting more airplay and she's (Debbie) reigning it in. Amazing. Like she would just destroy property over these stupid songs....She doesn't lose it the way she used to. I remember there was a worker that was driving her and one of their songs came on the radio and she had to pull off the road. (Grace June 25, 2017)

The last time the specific song came on the radio, Debbie did not have a tantrum. Even more amazing is that she could verbalize it to her mother.

Actually...the last time that this happened she acknowledged that she didn't lose it. She goes "Used to be...I would go crazy, but,...this time I didn't. (Grace June 25,2017 )

It is apparent that over the seven years that the specific song has been played on the radio, Debbie has gone from having violent tantrums every time she heard the song, to being able to soothe herself on occasion, and finally to be able to self-regulate her emotions and verbalize the experience. Although her mother Grace was worried about what the future holds for Debbie, she could see the progress.

Tom: self-regulation and social skills 
Tom is shy, but over the years in high-school, his participation in plays, musicals and festivals has helped him become more social. Tom judged in the festival in 2017 along with two other judges with whom he had to discuss the different performances. He also helps the drama teacher at his former school with plays.

I have one coming up next week too...She phoned me a few days ago...When she needs help, I go in to the school and I help her like with the sound and the lighting (Tom June 13th 2017)

When he graduated from high-school, Tom got a bursary from the school arts council. Since we had last met, he had gone to Mexico twice (in addition to the first time) with a group from school to paint. They wanted him to come back and teach English there. Tom has also travelled to Cuba for his graduation trip with classmates. He actually made both the honor roll and the principal's list when he graduated. Music has helped him in all of these accomplishments according to Patty.

Honey, there isn't any time that you don't have music on when you're doing some-thing. When you're writing something, when you're watching TV... (asking Tom) I don't know what Tom would have been like if he hadn't had any music. (Patty, June 13th 2017)

Over the years, music has helped Tom overcome barriers and become more socially involved in artistic activities of different sorts. He plays an important role in the performances when he does the sound and lighting, which also makes him socially included in that context and beyond. Tom has less contact with his culture now that he is older. However, this does not mean that he will not reconnect in the future. The reservation is close to the community which gives him easy access to visit.

\section{DISCUSSION}

Music is a wonderful thing, and for the three young First Nation persons on the autism spectrum in this project, it is of vital importance. For Connor, Indigenous music helps him calm down and relax. The use of culturally specific music from his tribe is essential for him and he has previously reacted positively to culturally sensitive music [8]. This has helped him to self-regulate his emotions [2]. When family members play and sing with him, they are in fact conducting an intervention within an Indigenous model of inclusive equitable special education [17]. Connor is minimally verbal, so the family must interpret his well-being and emotions from his behaviors. They are convinced that music from their culture is beneficial to him. Within an Indigenous worldview, he is then in connection with all in creation [14]. As Connor is banned from school and has no access to education, it lies on his family to provide such music interactions. In a literature review, supporting evidence was found that rhythmic and motor components in music therapy interventions improved speech production and the acquisition and processing of language [18]. For Connor, such culturally specific music-based activities involving traditional drumming and singing could offer much potential.

Debbie has had extreme aggressive outbursts when she hears a certain song that is believed to remind her of her father who has passed. Grief can be handled through music [3]. However, if there is another cause for the aggression when hearing the music, Debbie has gradually developed her ability to self-regulate her emotion and verbalize the experience [2] which has briefly been discussed previously [19]. Debbie lives off reserve in a community where she is relatively well-known and she uses music in various purposes throughout her everyday life. In this article, her ability to self-regulate her emotions is in focus. Debbie has had access to several services such as workers and an after-school club where music activities have been provided in addition to music in the school setting. Although she has not been able to say why she has become so agitated and upset by the particular song, over the years she has worked through the experience and is now managing to self-regulate her emotion. It has been found that individuals use music to maintain a happy mood and that this is usually a nonconscious strategy [20]. The song Debbie reacts to is not played by her choice, but comes on randomly on the radio, which means that she is not prepared to listen to it. This shows that Debbie has acquired the skills to handle her emotions when the song is played.

For Tom, music has been vital to his development of social skills [1]. By participating in musicals, but also managing sound and lighting, he has become a person to rely on in these settings. Research has shown that children who participate in musical theatre activities and perform first seek contact with adult leaders but eventually can interact more with each other in and outside of the musical context. This was in regard to children with and without disabilities. Parents reported that the children gained more confidence in daily activities in educational and community settings [21]. Although Tom is actively a part of the musicals with peers 
and leaders it would seem like it has not resulted in peer relationships outside of the musical context. However, he plays an important role in the productions which makes him involved and a key person.

Unfortunately, Debbie and Tom are quite estranged from their culture, and one can only speculate on the impact culturally sensitive or specific music interventions could have in their skill development. This could be an interesting direction for future research. Hopefully, the 4 th (and possibly $5^{\text {th }}$ ) wave of data collection in the follow-up project can provide richer material to illuminate this issue. In all three of the cases, it has been very much up to their families and themselves to initiate and provide the music activities and interventions. The careful and conscious planning of such activities by autism support services and within educational settings is an enticing idea that would provide research-based, culturally relevant and sensitive opportunities for skill development. The hypothesis for future research is therefore formulated as such; If Indigenous children with autism are provided with culturally relevant and sensitive music and other support services and interventions this will facilitate their skill development.

\section{Concluding remarks}

The main contribution of this article is to illuminate how music can facilitate the skill development of First Nations youth on the autism spectrum. There is still a dearth of research focusing on Indigenous individuals on the autism spectrum, which may stem from how ASD is viewed through a First Nations lens [8]. The medical deficit model of disability [8] may clash with Indigenous ways of knowing being and doing. Therefore, Indigenous and Indigenist models of inclusive equitable special education can offer insights and possibilities for First Nations individuals on the autism spectrum to reach their full potential [17].

\section{Acknowledgements}

I would like to express thanks and acknowledge the research partners in this project and my Indigenous family members who made this research possible. Furthermore, I would like to acknowledge the traditional knowledge holders, Elders and Indigenous researchers who have helped me in making a paradigm twist.

This research received funding from Stiftelsen Lars Hiertas Minne.

\section{References}

[1] Thomas KS. Music Preferences and the Adolescent Brain: A Review of Literature. Update: Applications of Research in Music Education. 2016;35(1):47-53. doi:10.1177/8755123315576534

[2] Saarikallio S. Music as emotional self-regulation throughout adulthood. Psychology of Music. 2011;39(3):307-327. doi:10.1177/0305735610374894

[3] Viper M, Thyrén D, Horwitz EB. Music as Consolation-The Importance of Music at Farewells and Mourning. OMEGA - Journal of Death and Dying. July 2020. doi:10.1177/0030222820942391

[4] dos Santos, A. (2019). Empathy and Aggression in Group Music Therapy with Teenagers: A Descriptive Phenomenological Study, Music Therapy Perspectives, 3 (1), 14-27, https://doi.org/10.1093/mtp/miy024

[5] Rabinowitch, T., Cross, I., \& Burnard, P. (2012). Long-term musical group interaction has a positive influence on empathy in children. Psychology of Music, 41, 484-498. doi:10.1177/0305735612440609

[6] American Psychiatric Association. (2013). Diagnostic and statistical manual of mental disorders (5th ed.). Arlington, VA: American Psychiatric Publishing.

[7] Molnar-Szakacs, I. \& Heaton, P. (2012). Music: a unique window into the world of autism. Annals of the New York Academy of Sciences. 1252, 318-324. DOI: 10.1111/j.1749-6632.2012.06465.x

[8] Lindblom, A. (2017a). Exploring autism and music interventions through a First Nations lens. AlterNativean International Journal of Indigenous Peoples. 13(4) 202-209 DOI:10.1177/1177180117729854

[9] Lindblom, A. (2017b). "It gives them a place to be proud" - Music and social inclusion. Two diverse cases of young First Nations people diagnosed with autism in British Columbia, Canada. Psychology of music, 45(2), p 268-282. DOI: 10.1177/0305735616659553

[10] Crown-Indigenous Relations and Northern Affairs Canada. (2021). Indigenous peoples and communities. Retrieved from: https://www.rcaanc-cirnac.gc.ca/eng/1100100013785/1529102490303 
[11] Indigenous Services Canada. (2021). What is Indian status? Retrieved from: https://www.sacisc.gc.ca/eng/1100100032463/1572459644986

[12] Lindblom, A. (2014). Under-detection of autism among First Nations children in British Columbia, Canada. Disability and Society, 29(8), 1248-1259. DOI: 10.1080/09687599.2014.923750

[13] Miranda, D., Blais-Rochette, C., Vaugon, K., Osman, M., \& Arias-Valenzuela, M. (2015). Towards a culturaldevelopmental psychology of music in adolescence. Psychology of Music, 43, 197-218. doi:10.1177/0305735613500700

[14] Wilson, Shawn. (2008). "Research is ceremony. Indigenous research methods". Halifax, NS, Canada: Fernwood Publishing.

[15] Adams, Dawn H, Shawn Wilson, Ryan Heavy Head, and Edmund W. Gordon. 2015. "Ceremony at a Boundary fire: a story of Indigenist Knowledge". Longmont, cO. Retrieved from: http://hdl.handle.net/2123/13689

[16] Beaudry, Jonas Sébastien. 2016. "Beyond (models of) disability". Journal of Medicine and Philosophy, 41: 210-228. doi:10.1093/jmp/jhv063

[17] Lindblom, A; Jannok Nutti, Y. (2021). "Conceptualizing Global Indigenous and Indigenist models of Inclusive Equitable Special Education." Manuscript accepted for publication.

[18] Janzen, Thenille Braun, Michael H. Thaut. Rethinking the role of music in the neurodevelopment of autism spectrum disorder. Music \& Science. January 2018. doi:10.1177/2059204318769639

[19] Lindblom, Anne. (2019). Rebalancing power relationships in research using visual mapping: examples from a project within an Indigenist research paradigm. PRACTICE. DOI:10.1080/25783858.2019.1589989

[20] Saarikallio Suvi. Music as emotional self-regulation throughout adulthood. Psychology of Music. 2011;39(3):307-327. doi:10.1177/0305735610374894

[21] Byrge, Kendall., Jordan Goodwin, Evalyn Estep, Tyler Smith, Amy Kurowski-Burt, and Grace Lauzon. Let's Work Together for Inclusion! A Musical Theater Program for Children. AJOT: American Journal of Occupational Therapy Vol. $\quad 74, \quad$ Issue http://dx.doi.org.bibproxy.kau.se:2048/10.5014/ajot.2020.74S1-P02129 